\title{
Quill barbed suture-related complication
}

\author{
Sonia Rombaut • Sonia Baulies • Maite Cusidó • \\ Pere Barri-Soldevila • Ignacio Rodriguez • Alicia Úbeda
}

Received: 21 February 2012 / Accepted: 28 April 2012 /Published online: 15 May 2012

(C) Springer-Verlag 2012

\section{Introduction}

In January 2007, a new concept in wound closure was introduced in the USA, the bidirectional barbed suture (Quill ${ }^{\circledR}$ SelfRetaining System, SRS: Angiotech Pharmaceuticals). Even though the materials are similar to the conventional suture (nylon, polypropylene and PDS), it has a revolutionary design. The Quill ${ }^{\circledR}$ SRS consists of a monofilament with tiny barbs cut into the length of the surface, self-anchoring to the tissue. This self-anchoring capacity eliminates the need for surgical knots and hysterorrhaphy becomes easier, therefore reducing surgical time and blood loss. Although Quill ${ }^{\circledR}$ SRS is more expensive, less suture is required for hysterorrhaphy compared with conventional suture, resulting in a better cost-effective alternative.

\footnotetext{
S. Rombaut $(\bowtie) \cdot$ S. Baulies $\cdot$ M. Cusidó $\cdot$ P. Barri-Soldevila $\cdot$

A. Úbeda

Gynecology Service, Department of Obstetrics,

Gynecology and Reproduction, Institut Universitari Dexeus,

Gran Via Carles III 71-75,

08028 Barcelona, Spain

e-mail: sonrom@dexeus.com

S. Baulies

e-mail: sonbau@dexeus.com

M. Cusidó

e-mail: maicus@dexeus.com

P. Barri-Soldevila

e-mail: barper@dexeus.com

A. Úbeda

e-mail: aliube@dexeus.com

I. Rodriguez

Statistics and Epidemiology Unit, Department of Obstetrics, Gynecology and Reproduction, Institut Universitari Dexeus, Gran Via Carles III 71-75,

08028 Barcelona, Spain

e-mail: nacrod@dexeus.com
}

In our centre, laparoscopic myomectomies are performed since 2002, and according to our results, they provide the same efficacy and are a safe and good alternative to laparotomic myomectomies [1]. We introduced the Quill ${ }^{\circledR}$ SRS in July 2010 and up to now 50 surgical procedures have been performed with this technique. Preliminary results of a comparative observational study carried out in our centre suggest that barbed suture reduces surgical time [2]. However, even though it is less time-consuming, we have observed a major complication in one case of a patient, requiring a reintervention. Taking into account the low complication rate associated with laparoscopic myomectomy (LM) and the low number of patients analysed, we considered important to describe the findings of our complication using the Quill ${ }^{\circledR}$ SRS suture.

\section{Case report}

A 30-year-old woman with no significant past medical history, familial or personal, was admitted to our facility. Her menarche was at 12 years old and she reported regular menses. There was no significant surgical history either.

The patient presented to our centre for a check-up, following a clinical course of hypermenorrhea with anaemia, which required medical treatment, and dysmenorrhea over several months. Physical examination showed an enlarged uterus with good mobility. The patient complained of pelvic pain during sexual intercourse. Transvaginal ultrasound scan revealed a retroverted uterus, measuring $88 \mathrm{~mm}$ in length, and the AP diameter of the fundus was $48 \mathrm{~mm}$. An intramural myoma of $68 \times 48 \mathrm{~mm}$ was observed in left anterior wall.

The clinical diagnosis was symptomatic uterine myoma, and the surgical procedure to be performed was laparoscopic myomectomy. Oblique hysterotomy was carried out through 
anterior uterine wall with subsequent enucleation of the myoma. Endometrial cavity was avoided. Closure of the cavity was performed using the new barbed suture Quill ${ }^{\circledR}$ SRS in two layers (1.0- and 36-mm needle, $14 \mathrm{~cm}$ long). First, the needle was passed through the distal portion of the hysterotomy, and by using an atraumatic grasper, one arm of the suture was pulled through the tissue until the transition point was reached, where the barbs change direction. With one arm of the device, the deeper layer of the myometrium was closed in a continuous fashion, and with the other arm, the seromuscular layer was closed also using a continuous suture. Both ends of the suture were cut with scissors at $0.5 \mathrm{~cm}$ from the uterine serosa. The myoma was morcellated and hemostasis was assured. Histological findings confirmed the diagnosis of uterine leiomyoma. The patient had good immediate postoperative recovery and was discharged 2 days later. Routine follow-up after surgery was uneventful.

Three weeks after myomectomy, the patient presented to our emergency room with $48 \mathrm{~h}$ of colicky abdominal pain and diarrheic stools. Examination revealed abdominal distention, painful on palpation and poor intestinal peristaltism. Blood tests showed leukocytosis $(19,400)$ and a PCR of $6.6 \mathrm{mg} / \mathrm{L}$. Abdominopelvic CT revealed an image of dilated loops of small bowel with a segment of ileal stenosis and was diagnosed as bridle with mild ascitis.

The patient was admitted for observation with a diagnosis of pseudo-obstruction and was treated with IV fluids, nasogastric tube suction and nothing by mouth. Twenty-four hours later, the patient presented paralytic ileus and no improvement of her symptoms, so a diagnostic laparoscopy was performed. The abdominal cavity showed a well-healed hysterorrhaphy from the previous myomectomy (Fig. 1), with a terminal ileal loop strangled at the mesothelial level with signs of revascularization near the promontory and the sigmoid colon was adhered to the left end of the hysterorrhaphy. The small bowel loop was strangled by the suture. Once dissected, normal colour was restored (Fig. 2). Liberation of the sigmoid colon from the surgical site was performed and indemnity of the serosa of the small intestine was confirmed, not requiring bowel resection. Twenty-four

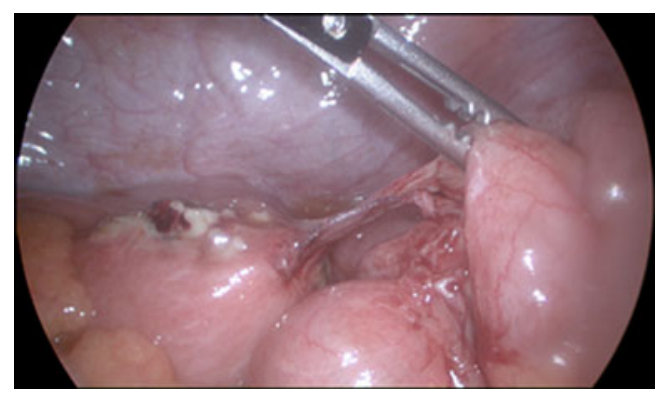

Fig. 1 Terminal ileal loop strangled at the mesothelial level

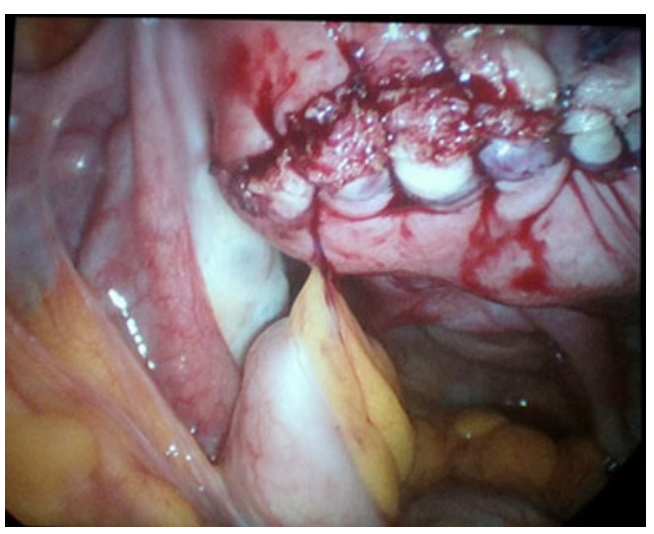

Fig. 2 Small bowel loop strangled by the suture

hours later, the patient had re-established peristaltism and was discharged on the fourth day. The patient is currently following normal check-ups and has a satisfactory clinical evolution, with no hypermenorrhea or dysmenorrhea.

\section{Comments}

LM was first performed in the late 1970s. The growing interest in recent years in minimally invasive surgery has motivated the development of LM, and it has become a technique with a widely validated efficacy and a safe alternative to laparotomic myomectomy. Surgical indications for myomectomy include symptomatic myomas, infertility-related myomas or asymptomatic but rapidly growing myomas [3].

Several randomised studies comparing laparotomic versus laparoscopic myomectomy have been published [4-7]. They all proved that laparoscopic approach involves less postoperative pain, reduced hospital stay, better recovery and less bleeding. No difference in recurrence was found, and regarding obstetric outcomes, pregnancy rates are the same, and no difference concerning the delivery route was noted, both techniques being used. However, the closure of the uterine incision in laparoscopy has always been quite controversial. It is necessary to guarantee the same results as in laparotomy hence the surgical technique is of great importance.

Barbed suture (Quill ${ }^{\circledR}$ SRS) is presented as a highly useful tool for minimally invasive surgeries. Its design allows for tissue approximation without the need to keep a constant tension and avoids intrasurgical knots. Several types of surgery can benefit from this tool. Barbed sutures are used in colporrhaphy of laparoscopic hysterectomies or peritonization of the mesh in sacrocolpopexy. Unlike other barbed sutures, the barbs of the Quill ${ }^{\circledR}$ SRS are set facing in opposite directions from the midpoint, also known as transition point, with a needle on each end. One of the arms of 
the suture is used for deep layer closure and the second arm is used for superficial or seromuscular layer closure.

The first studies where the surgical potential of this new type of suture is described have already been published. In 2010, Alessandri et al. [8] published the only prospective randomised study, with 44 cases, demonstrating that the barbed suture (V-Loc ${ }^{\circledR}$, Covidien) reduced surgical time and blood loss. Moreover, recent studies [9, 10] have also proved the advantages of this new wound closure system. Despite their efficacy in terms of a reduction in operating time during laparoscopic surgery, little is known about the adverse effects. Two complications of small bowel obstruction have been reported last year. One of them was a secondary laparoscopic vaginal cuff closure [11] and the other one was following peritoneal closure during laparoscopic sacral colpopexy [12].

The barbs of this suture, besides providing a self-anchoring capacity, have a high ability to adhere to the surrounding tissues. For this reason, we strongly insist in the importance of not leaving any free suture in the cavity and cutting the suture flush with the serosa. Despite documenting its selfanchoring capacity to the tissue, it is important not to exceed the transition point in order to avoid the suture to run loose. We recommend performing a loop before tension to reach the transition point to avoid shifts. 'Doubling back' at each suture end in order to have a complete closure is also advised by the company. In our case, we believe that the transition point was exceeded, possibly contributing to its shifting, leaving a suture-free margin in cavity and causing the adhesions of the bowel loops. On the other hand, our complication could also be explained by the swelling and posterior shrinkage of the tissues during the healing process.

According to our experience, laparoscopic myomectomy with barbed suture is a fast and effective procedure. The capacity to self-anchor to the tissue avoids the need to tie knots and allows for an even tension in the hysterorrhaphy. We believe it could significantly reduce operating time and improve our surgical outcomes, with a subsequent cost saving as well. However, it is important to emphasise the need to proceed with this suture technique following the care recommendations and paying special attention to not leaving free suture in the abdominal cavity. Further cases are needed to validate and reproduce the safety of the barbed suture.
Acknowledgments The authors wish to thank the members of the Servei de Ginecologia of Institut Universitari Dexeus in Barcelona for providing clinical data essential for the development of this study.

\section{References}

1. Baulies Caballero S, Cusido MT, Devesa de la Rua M, Rodríguez I, Fabregas Xaudaró R (2009) Laparoscopic versus laparotomic myomectomy. Prog Obstet Ginecol 52(1):25-31

2. Rombaut S, Barri-Soldevila P, Baulies S, Cusido M, Ubeda A (2010) The use of bidirectional barbed suture in laparoscopic myomectomy. Video presentation. Gynecol Surg 7(Suppl 1):S123S141 (V9 6)

3. Alessandri F, Lijoi D, Mistrangelo E, Ferrero S, Ragni N (2006) Randomized study of laparoscopic vs minilaparotomic myomectomy for uterine myomas. J Minim Invasive Gynecol 13:92-97

4. Mais V, Ajossa S, Guerriero S, Mascia M, Solla E, Melis GB (1996) Laparoscopic versus abdominal myomectomy: a prospective, randomized trial to evaluate benefits in early outcome. Am J Obstet Gynecol 175:654-658

5. Seracchioli R, Rossi S, Govoni F, Rossi E, Venturoli S, Bulletti C et al (2000) Fertility and obstetric outcome after laparoscopic myomectomy of large myomata: a randomized comparison with abdominal myomectomy. Hum Reprod 15(12):2663-2668

6. Rossetti A, Sizzi O, Soranna L, Cucinelli F, Mancuso S, Lanzone A (2001) Long-term results of laparoscopic myomectomy: recurrence rate in comparison with abdominal myomectomy. Hum Reprod 16(4):770-774

7. Nash K, Feinglass J, Zei C (2012) Robotic-assisted laparoscopic myomectomy versus abdominal myomectomy: a comparative analysis of surgical outcomes and costs. Arch Gynecol Obstet 285(2):435-440

8. Alessandri F, Remorgida V, Venturini PL, Ferrero S (2010) Unidirectional barbed suture versus continuous suture with intracorporeal knots in laparoscopic myomectomy: a randomized study. J Minim Invasive Gynecol 17(6):725-729

9. Einarsson JI, Chavan NR, Suzuki Y, Jonsdottir G, Vellinga TT, Greenberg JA (2011) Use of bidirectional barbed suture in laparoscopic myomectomy: evaluation of perioperative outcomes, safety, and efficacy. J Minim Invasive Gynecol 18(1):92-95

10. Deffieux X, Pachy F, Donnadieu AC, Trichot C, Faivre E, Fernandez H (2011) Péritonisation avec un fil cranté résorbable sans noeud en tours de promontofixation laparoscopique. J Gynecol Obstet Biol Reprod (Paris) 40(1):65-67

11. Donnellan MD, Mansuria MD (2011) Small bowel obstruction resulting from vaginal cuff closure with a barbed suture. J Minim Invasive Gynecol 18(4):528-530

12. Thubert T, Pourcher G (2011) Small bowel volvulus following pertoneal closure using absorbable knotless device Turing laparoscopic sacral colpopexy. Int Urogynecol J 22:761-763 